\title{
Preventive Effects of Resveratrol against Beta Adrenergic Catecholamine-Induced Acute Myocardial Stress during Experimental Hyperglycemia in in vivo and in vitro Models
}

\author{
S. Uma ${ }^{1}$ and M. Sreepriya ${ }^{1 *}$ \\ ${ }^{1}$ Department of Microbiology and Biotechnology, Bangalore University, Jnana Bharathi Campus, \\ Bangalore - 560 056, Karnataka, India.
}

Authors' contributions

This work was carried out in collaboration between the corresponding author MS and the first author SU. Author MS designed the study, decided on the objectives, interpreted the results and wrote the manuscript. Author SU managed the literature searches, performed all the experiments mentioned in

the manuscript and performed the statistical analysis. Both the authors read and approved the final manuscript.

\section{Article Information}

DOI: $10.9734 / C A / 2016 / 24929$

Editor(s):

(1) Wilbert S. Aronow, University of California, College of Medicine, Irvine, USA. (2) Fatih Yalcin, Fulbright Visiting Professor, School of Medicine, Department of Cardiology, Johns Hopkins University, USA.

(3) Francesco Pelliccia, Department of Heart and Great Vessels University La Sapienza, Rome, Italy. Reviewers:

(1) Aşkın Ender Topal, Dicle University, Turkey. (2) Gordon Kunbuma Tachang, University of Buea, Cameroon. (3) Jaroslaw Dudka, Medical University of Lublin, Poland. (4) Anonymous, Midwestern University, USA. Complete Peer review History: http://sciencedomain.org/review-history/14228

Original Research Article

Received $9^{\text {th }}$ February 2016 Accepted $6^{\text {th }}$ April 2016 Published $18^{\text {th }}$ April 2016

\section{ABSTRACT}

Aim: To evaluate the cardioprotective effects of resveratrol during hyperglycemic conditions in in vitro and in vivo models.

Study Design: H9c2 cardiomyocyte cells were used as in vitro models and adult male Wistar strain albino rats were used as in vivo models. Activities of LDH and levels of lipid peroxides, total reduced glutathione were the end point indicators for the in vitro studies. For the in vivo studies the activities of membrane bound ATPases, levels of lipid peroxides, enzymic and non enzymic 
antioxidants were the end point indicators.

Place and Duration of Study: The study was conducted at the Department of Microbiology and Biotechnology, Bangalore University, Bangalore, between January 2014 and June 2014.

Methodology: To mimic myocardial injury during diabetic conditions (in vitro), the H9c2 cells were maintained in high glucose environment followed by isoproterenol challenge. For in vivo studies the animals were segregated as follows: Untreated control; Myocardial stress induced animals (Isoproterenol $150 \mathrm{mg} / \mathrm{kg}$ body wt i.p); Diabetic rats (Streptozotocin, $50 \mathrm{mg} / \mathrm{kg}$ body wt,i.p); Myocardial stress induced diabetic rats; resveratrol per se (5 mg/kg.body wt. orally for 21 days), and resveratrol pretreated prior to induction of diabetes and myocardial stress.

Results: H9c2 cells given glucose insult and challenged with isoproterenol showed severe cytotoxicity and stress as elicited by increased LDH release, increased lipid peroxides and depleted GSH levels. These changes were prevented in the cells pretreated with resveratrol prior to isoproterenol/glucose challenge. The diabetic rats induced with myocardial stress showed significant alterations in the activity of membrane bound phosphatases, levels of lipid peroxides, enzymic and non enzymic antioxidants. Pre-treatment with resveratrol prevented these alterations thereby implicating cardioprotective effects during hyperglycemic conditions

Conclusion: Resveratrol could combat myocardial stress during experimental hyperglycemia in in vitro and in vivo models.

Keywords: Resveratrol; isoproterenol; myocardial stress; streptozotocin; type 1 diabetes.

\section{INTRODUCTION}

Free radicals play an important role in a number of biological processes, some of which are necessary for life, such as the intercellular killing of bacteria by phagocytic cells such as granulocytes and macrophages [1]. Free radical production occurs continuously in all cells as part of normal cellular function. However, excess free radical production originating from endogenous or exogenous sources might play a role in many diseases including diabetes and cardiovascular disease. There are a number of mechanisms to minimize the free radical induced damage and to repair the damage that occurs. The enzymic and non enzymic antioxidants play an important role in negating the damage induced by free radicals in biological systems [2]. Antioxidant supplementation has been proved to be beneficial to negate the oxidative damage induced in animals and humans.

Diabetes mellitus is a globally recognized modern day epidemic which is characterized by chronic hyperglycemia due to abnormal insulin secretion or insulin receptor and post receptor events affecting metabolism of carbohydrate, protein and lipids [3]. Patients with Diabetes mellitus are at increased risk for the development of cardiovascular diseases and other macrovascular complications. Enhanced oxidative stress and depleted antioxidant status in diabetics makes them highly vulnerable to cardiac injury and predispose them for myocardial infarction one of the lethal manifestations of cardiovascular disease [4]. Myocardial infarction remains the major cause of death in the developed and developing world and hence is a major pathological issue worldwide despite rapid advancements made in the treatment of Coronary Artery Diseases (CAD). According to the World Health Organization (WHO) myocardial infarction is predicted to be the major cause of mortality in the world by the year 2020 [5].

Streptozotocin is a glucosamine-nitrosourea compound. This compound is particularly toxic to the insulin-producing beta cells of the pancreas in mammals. It is extensively used in research to produce animal models for type-1 diabetes [6]. Streptozotocin (STZ) can induce in susceptible hosts direct beta cell cytotoxicity and cell mediated auto immune reactions [7]. These factors acting separately or in concert appear to induce destructive insulitis and severe diabetes in animals within a short span of time.

Isoproterenol (ISO) is a $\beta_{1^{-}}$and $\beta_{2^{-}}$ adrenoreceptor agonist that causes severe stress in the myocardium, resulting in infarct like necrosis of the heart muscle. Persistent beta adrenergic stimulation with isoproterenol leads to the development of oxidative stress, myocardial inflammation, thrombosis, platelet aggregation and calcium overload which ultimately culminates in myocardial infarction [8]. Isoproterenol being a dual $\beta_{1}$ - and $\beta_{2}$ adrenergic receptor agonist has, 
acute positive chronotropic and inotropic effects on the heart. When administered chronically or at high doses, isoproterenol has deleterious effects on the heart inducing hypertrophy, necrosis, fibrosis, apoptosis, oxidative damage and inflammatory cell infiltration [9]. On autooxidation isoproterenol generates highly cytotoxic free radicals known to stimulate peroxidation of membrane phospholipids and cause severe damage to the myocardial membrane [10]. Isoproterenol induced cardiac hypertrophy is a reliable, reproducible and well characterized model of cardiac hypertrophy associated with arrhythmias, myocyte loss, and fibrosis with the progression to heart failure [11].

In the recent years, antioxidants especially polyphenols have gained a lot of attention and have proved to be a promising strategy in the prevention of oxidative damage and cellular injury. Resveratrol(3,5,4'-trihydroxystilbene) a polyphenolic compound produced in the plants as a response to injury, ultraviolet irradiation, or fungal attack is a phytoalexin, phytoestrogen that is found mainly in the skin of grapes, mulberries and peanuts. Resveratrol is found to have diverse biological and pharmacological activities in vitro and as well as in vivo. It is reported to possess free radical scavenging [12], anticarcinogenic [13], anti-inflammatory [14], estrogenic activities [15] as well as cardiovascular protection [16] and neuroprotection [17]. Several lines of evidence from epidemiological studies revealed an inverse relationship between red wine consumption and the risk of cardiovascular diseases [18]. Numerous studies suggest that resveratrol inhibits lipid peroxidation of low density lipoprotein (LDL) prevents the cytotoxicity of oxidized LDL and protects cells against highly hydrophilic and lipophilic properties. It has been reported to provide more effective protection than other well-known antioxidants such as vitamin C and E [19]. The antioxidant effects of resveratrol are reported to contribute for its strong cardioprotective actions which have been experimentally proven in several experimental models of ischemia and myocardial infarction [20]. Reduced platelet aggregation and vasorelaxation has also been demonstrated in studies with resveratrol thereby indicating its thromobolytic actions and its possible role in cardio protection [21]. The vasorelaxant activity of resveratrol has been due to its ability to stimulate $\mathrm{Ca}^{2+}$ activated $\mathrm{K}^{+}$ channels and to enhance nitric oxide signaling in the endothelium.
An important aspect of myocardial $\mathrm{Na}^{+} \mathrm{K}^{+}$pump in heart disease is its influence on extracellular potassium homeostasis. Two important aspects should be considered: potassium handling among myocytes, and effects of potassium entering the extracellular space of the heart via the bloodstream. It should be noted that both of these aspects of $K_{e}$ homeostasis are affected by regulatory aspects, eg, regulation of the sodium/potassium pump by physiological and pathophysiological conditions, as well as by medical treatments. Peroxidation of membrane phospholipids not only alters the lipid mileu and structural as well as functional integrity of cell membranes, but also affects the various membrane bound enzyme activities including $\mathrm{Ca}^{2+}$ ATPase, $\mathrm{Mg}^{2+}$ ATPase and $\mathrm{Na}^{+} \mathrm{K}^{+}$ATPase $[22,23]$. As the membrane bound phosphatases play a major role in maintaining the integrity of cardiac membrane the present study was undertaken to understand the membrane protective and preconditioning effect of resveratrol against $\beta$-adrenergic stimulation during hyperglycemic conditions [24].

Although the cardio protective effects of resveratrol is well established, there are very few reports only on the effects of resveratrol in combating myocardial stress during diabetogenic conditions and currently there are no reports pertaining to the effects of resveratrol on the activities of membrane bound ATPases and antioxidant enzymes in diabetic animals induced with myocardial stress. Hence the objective of the current study is to evaluate the influence of resveratrol in protecting the myocardium against experimental injury induced by beta adrenergic stimulation with isoproterenol under hyperglycemic conditions. The results of the in vivo studies on rat models were compared with in vitro studies on rat cardiomyocyte models ( $\mathrm{H} 9 \mathrm{c} 2$ cells) to have a better understanding of the protective effects of resveratrol on cardiomyocytes.

\section{MATERIALS AND METHODS}

\subsection{Chemicals}

Isoproterenol (ISO), Streptozotocin (STZ/), Resveratrol (RSV) and Thiobarbituric acid (TBA) and Glutathione were purchased from Sigma Chemical Company, St.Louis, MO,USA. Sterile ready to use Dulbecco's Modified Essential Medium (DMEM - AL007), Fetal Bovine Serum (FBS- RM1112), Trypsin-EDTA (T-001), Antibiotic antimycotic solution (A002) were 
procured from Himedia Laboratories Pvt Limited, Mumbai, India. All the other chemicals used were of analytical grade and were purchased from the local chemical companies.

\subsection{Animals and Treatment}

Adult Wistar strain male albino rats weighing about $120 \mathrm{~g}-140 \mathrm{~g}$ were procured from the approved sources of Bangalore University (M/s Raghavendra Enterprises, Bangalore). They were kept under quarantine for a period of two weeks. The animals were maintained under standard laboratory conditions with 12 hrs night and day cycle and were fed with commercial pelleted rat chow (M/S Hindustan Lever Limited, Bangalore, India) and water ad libitum. This part of the study which involved the usage of animals was approved by the Institutional Animal Ethics Committee (IAEC), Bangalore University (Approval no: Dr MSP-SU/RP/IAEC/BUB dated 09/05/2011), Bangalore-560056.

\subsection{Procurement and Maintenance of $\mathrm{Hg}$ c2 Cell Line}

The cardiomyocyte cell line H9c2 was procured from the National Center for Cell Science, Pune, India and cultured in sterile ready to use Dulbecco's Modified Essential Medium (DMEM) supplemented with 10\% Fetal Bovine Serum and antibiotic antimycotic solution. Cells were grown under standard growth conditions (Temperature $37^{\circ} \mathrm{C}, 95 \%$ humidity and $5 \% \mathrm{CO}_{2}$ ) in a $\mathrm{CO}_{2}$ incubator (Forma Scientific, USA). When a confluent monolayer was formed, the cells were detached with $0.25 \%$ Trypsin- $0.2 \%$ EDTA in Dulbecco's phosphate buffered saline and then subcultured at a split ratio of $1: 3$ in a $12.5 \mathrm{~cm}^{2}$ tissue culture flask. The media was changed three times a week. The cells were grown in a growth medium containing $10 \%$ FBS or maintenance medium containing $5 \%$ FBS. On arriving at confluency, the cells were plated on to 96 well microtiter plates (TPP-96, Himedia, India) and were utilized for different in vitro assays.

\subsection{In vitro Assays for Assessing the Influence of Resveratrol on Cardiomyocyte Viability and Integrity}

Induction of hyperglycemic conditions and stress on cardiomyocyte cells in vitro by challenge with glucose and isoproterenol- In vitro models to mimic myocardial stress in diabetic conditions.
On arriving at confluency, the cells $\left(5 \times 10^{6}\right.$ cells $/ \mathrm{ml}$ ) were plated on to 96 well microtiter plate. The cells were allowed to attach overnight and then pretreated with resveratrol $(30 \mu \mathrm{g} / \mathrm{ml}$ for 30 minutes) $[25,26]$. Following this, experimental hyperglycemic conditions were induced in $\mathrm{H} 9 \mathrm{c} 2$ cells by exposing them to high concentration of glucose $(30 \mathrm{mM} / \mathrm{L})$ [27] for 24 hours. After 24 hours, the cells were treated with isoproterenol $(100 \mu \mathrm{moles} / \mathrm{L})$ for $8 \mathrm{hrs}$ [28]. A group of cells were challenged with glucose/isoproterenol at the same dose specified above and then treated with resveratrol ( $30 \mu \mathrm{g} / \mathrm{ml}$ for 30 minutes) to understand if resveratrol treatment could reverse the damage inflicted on the myocardium (post treatment schedule).

\subsubsection{Cytotoxicity assessment by LDH leakage}

After the different treatment periods, the effect of resveratrol pretreatment and post treatment on cell viability was determined by measuring the LDH leakage into the culture supernatant using a commercially available kit (Span Diagnostics, India) following the manufacturer's instructions.

\subsubsection{Estimation of lipid peroxides}

Lipid peroxide levels in the treated and untreated cells in vitro were determined by the method previously described by [29]. Briefly $200 \mu$ l of cell culture supernatant after the treatment was mixed with $0.5 \mathrm{ml}$ glacial acetic acid and $2.0 \mathrm{ml}$ of trichloro acetic acid was added and mixed well. The mixture was then centrifuged $(3000 \mathrm{~g})$ at room temperature for 10 minutes to separate the proteins. $2 \mathrm{ml}$ of the supernatant was taken, $0.5 \mathrm{ml}$ of $1 \%$ TBA was added to it followed by heating at $95^{\circ} \mathrm{C}$ for 60 minutes to generate the pink coloured malondialdehyde (MDA). The absorbance of the sample was read at $530 \mathrm{~nm}$. Results were expressed as $n$ moles of MDA/mg protein.

Malondialdehyde content of the heart tissue was measured according to the procedure of Ohkawa et al. [30] using 1,1,3,3 tetramethoxy propane as standard. Briefly, to $100 \mu \mathrm{l}$ of homogenate 200 $\mu \mathrm{l}$ of $8.1 \%$ SDS, $1.5 \mathrm{ml}$ of $20 \%$ acetic acid, $1.5 \mathrm{ml}$ of $0.8 \%$ aqueous TBA solution was added and the solution was made up to $4 \mathrm{ml}$. The solution was heated on boiling water bath for 60 minutes, cooled and $1 \mathrm{ml}$ of distilled water is added. $5 \mathrm{ml}$ butanol and pyridine (15:1) is added and the mixture was shaken well. The mixture was then centrifuged at $4000 \mathrm{rpm}$ for 10 minutes. The 
absorbance of orange layer was read at $532 \mathrm{~nm}$. Results were expressed as $\mathrm{n}$ moles of $\mathrm{MDA} / \mathrm{mg}$ protein.

\subsubsection{Estimation of total reduced glutathione (GSH)}

The non-enzymatic antioxidant reduced glutathione was determined following the protocol described by Moron et al 1979 [31]. $1.0 \mathrm{ml}$ of cell culture supernatant of treated and untreated cells (for in vitro studies) or heart tissue homogenate (for in vivo studies) were precipitated with $1.0 \mathrm{ml}$ of TCA and the precipitate was removed by centrifugation. To 0.5 $\mathrm{ml}$ of supernatant, $2.0 \mathrm{ml}$ of DTNB was added and the total volume was adjusted to $3.0 \mathrm{ml}$ with phosphate buffer. The absorbance was read at $412 \mathrm{~nm}$. Results were expressed as $\mathrm{n}$ moles of $\mathrm{GSH} / \mathrm{mg}$ protein.

\subsection{Segregation of the Experimental Animals for in vivo Studies and Biochemical Assays}

After the quarantine period, the animals were divided into six groups according to the following experimental regimen. Group 1 comprised control animals. Group 2 comprised animals which were induced with myocardial stress by giving two intraperitoneal injections of isoproterenol $(150 \mathrm{mg} / \mathrm{kg}$ body $\mathrm{wt} / \mathrm{day}$ in physiological saline) at an interval of $24 \mathrm{hrs}$. Group 3 animals were induced with diabetes by giving a single intraperitoneal injection of STZ (50 $\mathrm{mg} / \mathrm{kg}$ body wt/day). Group 4 were animals which were induced with myocardial stress after the induction of diabetes. Precisely, these groups of animals were administered with STZ at the specified dose. 48 hours after the injection of STZ, fasting blood sugar was determined in the animals. Animals which had glucose levels of $>$ $200 \mathrm{mg} / \mathrm{dl}$ were considered diabetic [32]. Such animals were selected for the induction of myocardial stress by the injection of isoproterenol. Group 5 were animals which were treated with resveratrol $(5 \mathrm{mg} / \mathrm{kg}$ body wt. /day orally for 21 days. Group 6 were rats which were pretreated with resveratrol $(5 \mathrm{mg} / \mathrm{kg}$ body wt. orally for 21 days) prior to the induction of diabetes and myocardial stress. (This dose was fixed based on preliminary studies conducted to understand the dose and time response of resveratrol in protecting the myocardium based on the activities of creatinine kinase in the serum of control and other groups of animals). Throughout the experimental period, the body weight of the animals were recorded and food intake monitored by visual observation at regular intervals.

After the experimental period (36 hrs after the second injection of isoproterenol) the animals were sacrificed following the guidelines specified by the IAEC. The thoracic cavity of the animals were opened, the heart was dissected out, washed with ice-cold isotonic saline and then blotted to dryness. The weight of the heart was measured and recorded for the different groups of the animals. The cardiac tissue obtained from different groups of animals was homogenized in $50 \mathrm{mM}$ phosphate buffer ( $\mathrm{pH}$ 7.0). Supernatant was used for assaying the activities of membrane bound phosphatases viz., Calcium ATPase [33], Sodium Potassium ATPase [34] and Magnesium ATPase [35]. The activities of Glutathione peroxidase [36], levels of total reduced glutathione [31] and lipid peroxides [30] were also estimated in the heart of the treated animals and untreated control animals.

\subsection{Statistical Analysis}

For in vitro assays all the experiments were carried out in triplicate on at least three different occasions and the mean of the replicate values were taken. Values were expressed as mean \pm SD $(n=6)$. Statistical analysis of the data was determined by Student's t-test, $P$ values were determined and comparisons were made between the untreated control cells and the treated cells.

For in vivo experiments statistical analysis was carried out by Student's $t$-test and values were expressed as mean \pm SD (for six animals in each group). The $P$ values were determined and intergroup comparisons were made. Comparisons were made between Group 2, 3, 4, 5 Vs Group 1; Group 6 Vs Group 4.

\section{RESULTS}

\subsection{Effect of Resveratrol Treatment on LDH Release during High Glucose Challenge Followed by Stimulation of H9c2 Cells with Isoproterenol}

Fig. 1 shows the effect of resveratrol pre and post treatment $(30 \mu \mathrm{g} / \mathrm{ml}$ for 30 minutes prior to glucose/isoproterenol challenge or after challenge with glucose/isoproterenol as the case may be) on LDH release in $\mathrm{H} 9 \mathrm{c} 2$ cells. Results 
indicate that the cells treated with high concentration of glucose followed by stimulation with isoproterenol resulted in loss of membrane integrity, increased permeability of the membrane resulting in increased leakage of LDH which was found to be statistically significant $(P$ $<0.001)$. Pretreatment with resveratrol was able to preserve the integrity of the myocardial membrane as elicited by the decreased leakage of $\mathrm{LDH}$ into the culture supernatant as compared to the glucose/isoproterenol challenged group of cells and exhibiting nonsignificant changes when compared with untreated control. H9c2 cells treated only with resveratrol did not show any significant increase in the release of $\mathrm{LDH}$ as compared to the control thereby showing the absence of adverse toxic effects of resveratrol at the dose employed. The group of cells post treated with resveratrol after challenge with glucose and isoproterenol also showed a significant increase in the leakage of LDH. This implicate that resveratrol post treatment is ineffective to reverse the damage induced by glucose/isoproterenol and its effects on the myocardium is preventive rather than curative.

\subsection{Effect of Resveratrol Treatment on the Levels of Lipid Peroxides and Total Reduced Glutathione during High Glucose Challenge Followed by Stimulation of $\mathrm{H} 9 \mathrm{c2}$ Cells with Isoproterenol}

Table 1 shows the levels of lipid peroxides and total reduced glutathione during glucose/isoproterenol challenge in H9c2 cells. Results indicate that the group of cells treated with glucose/isoproterenol showed clear signs of oxidative stress and peroxidative damage as elicited by the increased levels of lipid peroxides and depleted glutathione levels as compared to untreated control cells $(P<0.001)$. Cells pretreated with resveratrol were protected against this oxidative damage which is supported by the enhanced glutathione status and reduced lipid peroxide levels as compared to glucose/isoproterenol challenged $\mathrm{H} 9 \mathrm{c} 2$ cells. Post treatment of the cells with resveratrol following glucose/isoproterenol challenge failed to protect the cells against the oxidative damage which is evident from the statistically significant increase in the lipid peroxides and total reduced glutathione levels as compared to untreated control and nonsignificant changes with respect to lipid peroxide levels as compared to isoproterenol challenged cells exposed to high glucose.

\subsection{Effect of Resveratrol on the Activities of Membrane Bound Phosphatases in the Heart of Control and Experimental Animals}

Table 2 shows the effects of resveratrol (RSV) on the activities of membrane bound phosphatases $\left(\mathrm{Na}^{+} \mathrm{K}^{+}\right.$ATPase, $\mathrm{Ca}^{2+}$ ATPase and $\mathrm{Mg}^{2+}$ ATPase) in the heart tissue of different groups of rats. Results implicate that the activity of $\mathrm{Na}^{+}{ }^{1} \mathrm{~K}^{+}$ ATPase showed a decrease, whereas the $\mathrm{Ca}^{2+}$ ATPase and $\mathrm{Mg}^{2+}$ ATPase showed an increase in the Group 2 (ISO only) and Group 4 (ISO + STZ) rats as compared to the untreated control rats. The change in enzyme activity observed in Group 2 and Group 4 rats was found to be statistically significant $(P<0.001)$. The Group 5 rats given resveratrol per se did not show any significant change in the activities of all the three membrane bound phosphatases studied as compared to the Group 1 control animals thereby implicating the nontoxic effects of resveratrol on the myocardium at the dose employed. The Group 6 diabetic rats pretreated with resveratrol for 21 days prior to the induction of myocardial stress showed an increase in the activity of sodium potassium ATPase concomitant with a decrease in the activities of Calcium ATPase and Magnesium ATPase as compared to that of Group 4 (ISO + STZ) animals thereby implicating the ability of resveratrol to prevent the detrimental changes in the myocardial membrane during isoproterenol challenge under experimentally induced hyperglycemic conditions.

\subsection{Effect of Resveratrol on the Levels of Lipid Peroxides (LPO), Total Reduced Glutathione (GSH) and Activity of Glutathione Peroxidase (GPx) in the Heart of Normal and Experimental Groups of Rats}

Table 3 shows the levels of lipid peroxides, total reduced glutathione and the activity of glutathione peroxidase in the heart of control and experimental groups of rats. The levels of lipid peroxides showed a statistically significant $\left(P_{<}\right.$ 0.001 ) increase in the Group 2, 3 and 4 rats as compared to the untreated control. The Group 5 rats given resveratrol per se showed nonsignificant changes in the levels as compared to the Group 1 control animals. The Group 6 rats pretreated with resveratrol for 21 days prior to the induction of myocardial stress showed a significant decrease in the levels of lipid 
peroxides in the heart as compared to the Group 4 rats thereby indicating the antiperoxidative

effects of resveratrol and its inhibitory effect of lipid peroxidation chain reaction.

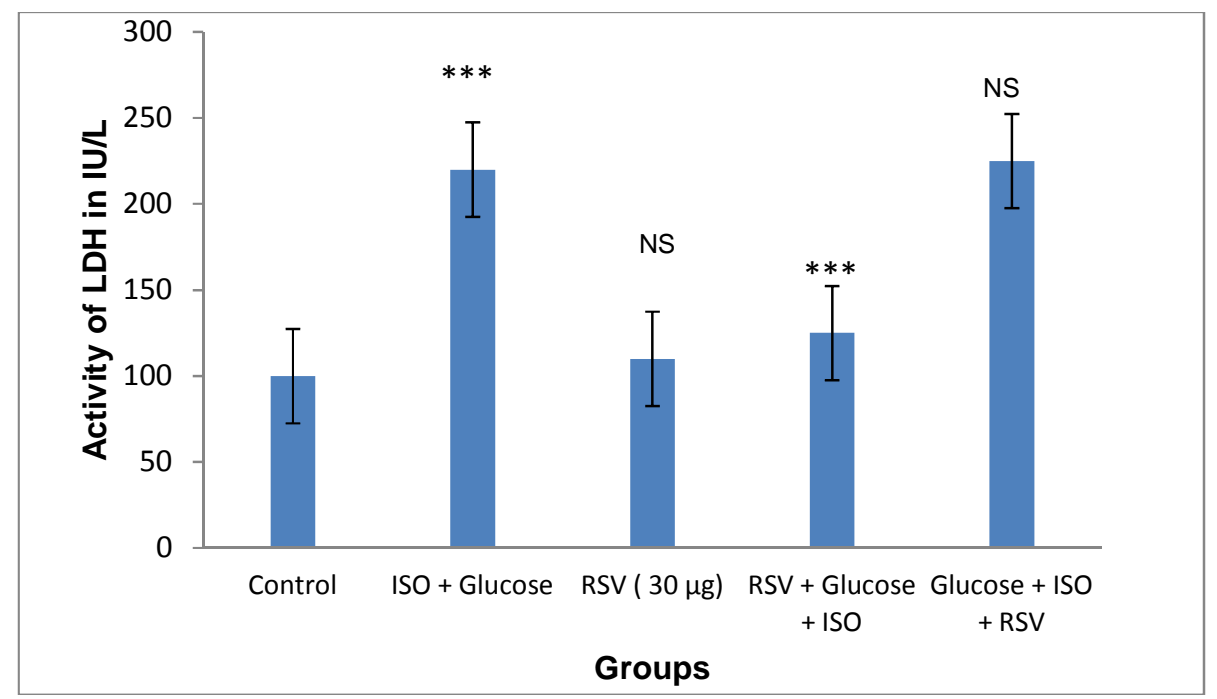

Fig. 1. Effect of resveratrol on LDH leakage during high glucose/isoproterenol challenge in H9 c2 cells

Values were expressed as mean $\pm S D(n=6)$. Statistical analysis by Students'- $t$ - test. Comparisons were made between Group 1 Vs Group 2; Group 3 and Group 2 Vs Group 4; Group 5. ${ }^{* * *} P<0.0011^{* N}$ - Non significant. Activity of $L D H$ expressed as IU/L

Table 1. Effect of resveratrol on the levels of lipid peroxides and total reduced glutathione during high glucose/isoproterenol challenge in H9c2 cells

\begin{tabular}{|c|c|c|}
\hline Groups & Lipid peroxides (LPO) & Total reduced glutathione (GSH) \\
\hline$\overline{1}$ & $0.29 \pm 0.05$ & $0.61 \pm 0.05$ \\
\hline 2 & $0.71 \pm 0.08^{\mathrm{mx}}$ & $0.27 \pm 0.04^{\mathrm{nmx}}$ \\
\hline 3 & $0.24 \pm 0.03^{x}$ & $0.68 \pm 0.06^{\mathrm{NS}}$ \\
\hline 4 & $0.49 \pm 0.04^{\mathrm{xx}}$ & $0.54 \pm 0.03^{\mathrm{nxx}}$ \\
\hline 5 & $0.69 \pm 0.08^{\text {NS }}$ & $0.31 \pm 0.02$ \\
\hline
\end{tabular}

Table 2. Effect of resveratrol treatment on the activities of membrane bound phosphatases in the untreated control and treated groups of rats

\begin{tabular}{|c|c|c|c|}
\hline Groups & $\mathrm{Na} / \mathrm{K}^{+}$ATPase & $\mathrm{Ca}^{2+}$ ATPase & $\mathrm{Mg}^{2+}$ ATPase \\
\hline 1 & $5.36 \pm 0.61$ & $1.46 \pm 0.2$ & $6.89 \pm 0.75$ \\
\hline 2 & $2.20 \pm 0.35^{\mathrm{kx}}$ & $6.31 \pm 0.50^{\mathrm{xax}}$ & $10.58 \pm 1.23^{x \pi x}$ \\
\hline 3 & $3.10 \pm 0.37^{x \times x}$ & $4.01 \pm 0.46^{\operatorname{nxx}}$ & $9.54 \pm 0.82^{x \times \pi}$ \\
\hline 4 & $1.91 \pm 0.20^{\mathrm{xx}}$ & $6.98 \pm 0.53^{\mathrm{xx}}$ & $10.72 \pm 1.96^{x \times x}$ \\
\hline 5 & $4.11 \pm 1.50^{\mathrm{NS}}$ & $1.76 \pm 0.28^{\text {NS }}$ & $6.97 \pm 0.78^{\text {NS }}$ \\
\hline 6 & $3.67 \pm 0.25^{x x}$ & $2.20 \pm 0.36^{\mathrm{xx}}$ & $8.52 \pm 0.93^{x}$ \\
\hline
\end{tabular}

Values were expressed as mean $\pm S D(n=6)$. Statistical analysis by Students'- $t$ - test. Inter group comparisons were made. Comparisons were made between Group 2, Group 3, Group 4, Group 5 Vs Group 1; Group 6 vs

Group 4. ${ }^{* * *} P<0.001 ;{ }^{*} P<0.05 ;{ }^{N S}$ - Non significant. Activity expressed as units: $\mu$ mol of phosphorus liberated $/ \mathrm{min} / \mathrm{mg}$ protein 
Table 3. Effect of resveratrol pretreatment on the levels of lipid peroxides, total reduced glutathione (GSH) and activity of Glutathione peroxidase during isoproterenol induced myocardial stress in diabetic rats

\begin{tabular}{|c|c|c|c|}
\hline Groups & $\begin{array}{l}\text { Lipid peroxides } \\
\text { (nmoles/mg of protein) }\end{array}$ & $\begin{array}{l}\text { Gpx } \\
\text { ( } \mu \text { g of GSH } \\
\text { consumed } / \mathrm{min} / \mathrm{mg} \text { protein) }\end{array}$ & $\begin{array}{l}\text { GSH } \\
\text { (n moles/mg protein) }\end{array}$ \\
\hline 1 & $0.42 \pm 0.06$ & $41.3 \pm 1.0$ & $35.7 \pm 0.5$ \\
\hline 2 & $0.68 \pm 0.08^{* * *}$ & $31.7 \pm 0.7^{\star \star \star}$ & $24.5 \pm 0.9^{\star \star \star}$ \\
\hline 3 & $0.84 \pm 0.04^{\star \star *}$ & $29.7 \pm 0.9^{\star \star *}$ & $29.5 \pm 2.0$ *** \\
\hline 4 & $1.37 \pm 0.02^{* \star * t}$ & $16.8 \pm 0.4^{\star \star \star}$ & $18.2 \pm 2.0^{\star \star \star}$ \\
\hline 5 & $0.48 \pm 0.10^{\mathrm{NS}}$ & $43.9 \pm 0.8^{\mathrm{NS}}$ & $36.2 \pm 2.2^{\mathrm{NS}}$ \\
\hline 6 & $0.38 \pm 0.06^{\star \star \star}$ & $34.9 \pm 0.9^{* * *}$ & $32.3 \pm 4.9^{\star \star *}$ \\
\hline
\end{tabular}

Interestingly, it was found that the levels of lipid peroxides of Group 6 rats were much reduced than the control showing a strong antiperoxidative effect.

The results also indicate that the Group 2, 3 and 4 rats showed a significant depletion in GSH $(P<$ 0.001) levels concomitant with a significant decrease in the activity of glutathione peroxidase $(P<0.001)$ as compared to the untreated control rats. This indicate the defective antioxidant status in diabetic rats and diabetic rats induced with myocardial stress. The Group 5 rats given resveratrol per se did not show any significant change in the activity of glutathione peroxidase and total reduced glutathione as compared to the Group 1 control animals. This indicate the absence of any adverse changes on treatment with resveratrol. The Group 6 rats pretreated with resveratrol for 21 days prior to the induction of myocardial stress showed a significant increase in the activity of glutathione peroxidase coupled with an enhancement in the levels of GSH in the heart thereby confirming the strong antioxidant effects of resveratrol as a result of which there is a replenishment in the levels of glutathione and normalization of glutathione antioxidant defense hence preventing the oxidative tissue damage in animals.

\section{DISCUSSION}

Nutrition can play an important role in the modulation of pathological conditions and thus can delay the onset and progression of many dreadful diseases in humans. Nutritional support and dietary intervention has always proven to be an important therapeutic strategy in the management of many life style diseases including diabetes and cardiovascular diseases. Antioxidants have gained considerable research importance in the recent years owing to their health benefits and multifaceted protective effects. Resveratrol is a phytoalexin, polyphenolic antioxidant and phytoestrogen reported to possess cardio protective properties owing to its strong antioxidant effect. It is a major component in red wine and is believed to be responsible for the low incidence of cardiovascular diseases in the French, in spite of consumption of a high fat diet. Several studies in the last two decades have demonstrated that resveratrol may prevent or slow the progression of a wide variety of human diseases including cancer, cardiovascular diseases, and ischemic injuries as well as to enhance stress resistance and extend the life span of a variety of organisms from yeast to vertebrates [37]. In the current study the ability of resveratrol treatment to protect the myocardium against beta adrenergic stimulation during experimentally induced diabetic conditions was investigated in in vivo and in vitro models. This will enable to understand if resveratrol supplementation could be beneficial in diabetic population predisposed to develop cardiovascular disease in the later part of life.

The myoblast cell line $\mathrm{H} 9 \mathrm{c} 2$, derived from embryonic rat heart [38] has been used as an in vitro model for both skeletal and cardiac muscle. H9c2 cells show electrophysiological and biochemical properties of both skeletal and cardiac tissues, including depolarization in response to acetylcholine, and rapid activation of calcium currents through L-Type channels. An interesting feature of this cell line is its ability to differentiate from mono nucleated myoblasts to 
myotubes upon reduction of serum concentration [39]. During the differentiation process, these cells retain several elements of the electrical and hormonal signaling pathway of cardiac cells [38]. and have therefore become an accepted in vitro model to study the effects of ischemia and diabetes on the heart [40].

In the current study, the efficacy of resveratrol pretreatment to maintain membrane integrity was determined by measuring the activity of lactate dehydrogenase (LDH) in the culture supernatant following high glucose/isoproterenol challenge. LDH is normally present in the cytosol, and cannot be measured extracellularly unless cell membrane damage has occurred. It has been shown that changes in metabolic activity are better indicators of early cell injury and that effects on membrane integrity are indicative of more serious injury leading to cell death. Increased leakage of LDH into the culture supernatant following treatment of $\mathrm{H} 9 \mathrm{c} 2$ cells with high glucose/isoproterenol implicate the severity of myocardial membrane damage inflicted experimentally thereby resulting in a leaky myocardial membrane. Reduced levels of LDH in cells pretreated with resveratrol prior to induction of stress on the cells, indicate the strong cytoprotective/cardio protective effects of resveratrol. This could be attributed to the previously reported pharmacological preconditioning effect of resveratrol eliciting appreciable protective effects [41]. Failure to prevent the leakage of LDH in cells post treated with resveratrol following high glucose/isoproterenol challenge indicate that the protective effects offered by resveratrol is preventive rather than curative.

Myocardial injury during diabetes is accompanied by increased oxidative stress, depleted antioxidant status and per oxidative membrane damage. Hence to understand the ability of resveratrol to prevent myocardial stress and lipid peroxidation, the levels of total reduced glutathione and lipid peroxides were estimated in the current study. Enhanced lipid peroxidation and depletion in the levels of total reduced glutathione are suggestive of severe oxidative stress and defective antioxidant status in the H9c2 cells given high glucose/isoproterenol insult. Resveratrol pretreatment very effectively prevented the depletion of thiol status and inhibited the lipid peroxidation reaction which could be attributed to the strong antioxidant effects of resveratrol. As observed with LDH leakage, post treatment of the cells with resveratrol was ineffective in repairing the damage inflicted by challenge with high glucose/isoproterenol thereby reiterating that resveratrol treatment is very effective in preventing the damage rather than repairing the damage induced in the myocardium.

This was further supported by the results of in vivo studies on rats in which pretreatment with resveratrol was able to efficiently prevent lipid peroxidation and improve glutathione antioxidant defense status thereby protecting the myocardium against oxidative stress induced by isoproterenol in diabetic rats. Hence the results of in vivo studies were in agreement with the in vitro studies and complement each other.

Free radical production occurs continuously in all cells as part of normal cellular function. However, excess free radical production originating from endogenous or exogenous sources might play a role in many diseases. The degree of tissue damage persuaded by free radicals depends on the balance between free radical generation and the endogenous antioxidant defense mechanism [42]. Antioxidants prevent free radical induced tissue damage by preventing the formation of radicals, scavenging them or by promoting their decomposition [43]. This could be the reason for the decreased lipid peroxide levels and increased glutathione status in the cells treated with resveratrol prior to the induction of stress. It has been reported that resveratrol is an efficient scavenger of $\mathrm{OH}^{-}$and $\mathrm{O}_{2}^{-}$radicals [44] that could account for its cardio protective effects. GSH is a major intracellular non protein sulfhydryl compound and is accepted as the most important intracellular hydrophilic antioxidant [45]. GSH acts as a cosubstrate for glutathione peroxidase and as a cofactor for many enzymes. Stress resistance of many cells is associated with high intracellular levels of GSH. A decreased GSH content may predispose the cells to lower defense against condition of oxidative stress during several degenerative disease conditions including aging and diabete $[46,47]$. The replenishment in glutathione status coupled with an enhancement in glutathione peroxidase activity in the resveratrol pretreated animals implicate the ability of resveratrol to negate the oxidative damage and maintain the antioxidant status thereby exerting its protective effects on the heart.

Further, to understand the effects of resveratrol in modulating the functions of ionic pumps and thereby regulate the movement of sodium, 
potassium, calcium and magnesium into and out of the cell, the activities of membrane bound phosphatases were investigated in the control and experimental groups of animals. ATPases are lipid dependent, membrane-bound enzymes involved in active transport process and have been implicated in the pathogenesis [48] of several diseases. Alterations in the activities of membrane bound enzymes are reported to affect the function of the heart. Vajreshwari et al. [49] reported that the failure of the cell membrane to maintain normal transmembrane ionic distribution through ion pumps is considered to be a major event in the pathogenesis of ischemia and arrhythmia. The role that $\mathrm{Na}^{+} / \mathrm{K}^{+}$-ATPase plays in $\mathrm{Na}^{+}$and $\mathrm{K}^{+}$antiport through the sarcolemma, in cation-homeostasis in cardiomyocytes as well as in excitation contraction coupling and cell signaling in the myocardium is now widely recognized. The current study attempts to understand the role of resveratrol in modulating the activities of membrane bound ATPases thereby exhibiting cardio protection during experimental myocardial stress in diabetic animals. Decreased activity of $\mathrm{Na}^{+} / \mathrm{K}^{+}$-ATPase observed in the study in the Group 2 (ISO only), Group 3 (STZ only) and Group 4 (ISO + STZ) rats could be due to enhanced lipid peroxidation induced by Isoproterenol or Isoproterenol/STZ [50]. This in turn can lead to a decrease in sodium efflux, thereby altering membrane permeability [51]. $\mathrm{Ca}^{2+}$ ATPase is another membrane bound phosphatase that regulates the actions of the calcium pump [52]. Enhanced $\mathrm{Ca}^{2+-}$ ATPase activity observed in Group 2 (ISO only) and Group 4 (ISO + STZ) rats could be due to the activation of adenylate cyclase by the isoproterenol. $\mathrm{Mg}^{2+}$ ATPase activity is involved in many energy requiring processes in the cell and its activity is sensitive to lipid peroxidation [48]. In the current study, pretreatment with resveratrol normalized the activities of these membrane bound enzymes in Group 6 (RSV+ISO+STZ) rats as compared to Group 4 (ISO + STZ) rats. Restoration of $\mathrm{Na}^{+} / \mathrm{K}^{+}$ATPase activity due to resveratrol pretreatment in the Group 6 (RSV+ISO+STZ) rats induced with myocardial stress could help to regulate the intracellular $\mathrm{Ca}^{2+}$ levels, thereby maintaining the membrane integrity and protecting the myocardium from damage rendering it non leaky.

\section{CONCLUSION}

Overall, the present study suggests that pretreatment with the polyphenol resveratrol preserves the cardiomyocytes against damage inflicted by experimental injury and oxidative stress. Resveratrol pretreatment in animals modulate the activities of membrane bound phosphatases, enhances the antioxidative status and inhibits lipid peroxidation chain reaction and thereby protect myocardial membrane integrity. The protective effects of resveratrol observed on the myocardium are strongly believed to be preventive rather than curative. Avenues are wide open for resveratrol to be explored as a potent cardio protective agent during diabetic conditions.

\section{CONSENT}

It is not applicable.

\section{ACKNOWLEDGEMENTS}

The financial assistance provided to this work in the form of research fellowship to Uma. S by Bangalore University, Bangalore is gratefully acknowledged.

\section{COMPETING INTERESTS}

Authors have declared that no competing interests exist.

\section{REFERENCES}

1. Pacher P, Beckman JS, Liaudet L. Nitric oxide a peroxynitrite in health and disease. Physiol Rev. 2007;87(1):315-424.

2. Halliwell B, Gutteridge JM. Lipid peroxidation, oxygen radicals, cell damage and antioxidant therapy. Lancet. 1984; 1(8391):1396-7.

3. Diagnosis and classification of diabetes mellitus: Report of the American Diabetes Association. Diabetes Care. 2008;31:555560.

4. Wolff SP. Diabetes mellitus and free radicals. Free radicals, transition metals and oxidative stress in the aetiology of diabetes mellitus. Br Med Bull. 1993;49(3): 642-52

5. Murray CJ, Lopez AD. Alternative projections of mortality and disability by cause 1990-2020: Global Burden of Disease Study. Lancet. 1997;349(9064): 1498-504.

6. Takada J, machado MA, Peres SB, Brito LC, Borges-silva CN, Costa CE, et al. Neonatal streptozotocin-induced diabetes 
mellitus: A model of insulin resistance associated with loss of adipose mass. Metabolism. 2007;56(7):977-984.

7. Skudelski T. The mechanism of alloxan and streptozotocin action in B cells of the rat pancreas. Physiol Res. 2001;50(6):53746.

8. Garg M, Khanna D. Exploration of pharmacological interventions to prevent isoproterenol-induced myocardial infarction in experimental models. Ther Adv Cardiovasc Dis. 2014;8(4):155-169.

9. Heather LC, Catchpole AF, Stuckey DJ, Cole MA, Carr CA, Clarke K. Isoproterenol induced in vivo functional and metabolic abnormalities: Similar to those found in the infarcted rat heart. J Physiol. Pharmacol. 2009;60(3):31-39.

10. Kesarwani N, Azmi L. Evaluation of cardioprotective effect of Tinospora cardifolia against isoprenaline induced myocardial infarction in rats. Int. J. Curr. Microbiol. App. Sci. 2014;3(3):543-555.

11. Krenek $P$, Kmecova J, Kucerova D, Bajuszova Z, Musil P, Gazova A, Ochodnicky P, Klimas J, Kyselovic J. Isoproterenol-induced heart failure in the rat is associated with nitric oxidedependent functional alterations of cardiac function. European $\mathrm{J}$ of Heart Failure. 2009;11(2):140-146.

12. Jia Z, Zhu H, Misra BR, Mahaney JE, Li Y, Misra HP, et al. EPR Studies on the super oxide scavenging capacity of the neutraceutical resveratrol. Mol Cell Biochem. 2008;313(1-2):187-94.

13. Bhardwaj A, Sethi G, Vadhan RS, Buesco Ramos C, Takada Y, Gaur U, et al. Resveratrol inhibits proliferation, induces apoptosis and overcomes chemoresistance through down regulation of STAT 3 and nuclear factor-Kappa B regulated antiapoptotic and cell survival gene products in human myeloma cells. Blood. 2007;109(6):2293-302.

14. Wang L, O MA, X Chen, Msha, Z MA. Effect of resveratrol on calcium regulation in rats with severe acute pancreatitis complication. European Journal of Pharmacology. 2008;580(1-2):271-276.

15. Bhat KP, Lantvit D, Christov K, Mehta RG, Moon RC, Pezzuto JM, et al. Estrogenic and antiestrogenic properties of resveratrol in mammary tumor models. Cancer Res. 2001;61(20):7456-63.
16. Das DK, Maulik N. Resveratrol in cardioprotection. Molecular Intervention. 2006;6(1):36-45.

17. Ates O, Cayli S, Altinoz E, Gurses I, Yucel $N$, Sener $M$, et al. Neuroprotectin by resveratrol against traumatic brain injury in rats. Mol Cell Biochem. 2007;294(1-2):137144.

18. Lin JK, Tsai SH. Chemoprevention of cancer and cardiovascular disease by resveratrol. Proc Natl Sci Counc Repub China B. 1999;23(3):99-106.

19. Chanvitayapongs S, Draczynska-Lusiak B, Sun AY. Amelioration of oxidative stress by antioxidants and resveratrol in PC12 cells. Neuroreport. 1997;8(6):1499-502.

20. Vidavalur R, Otani H, Pawan K. Singal, Nilanjana Maulik. Significance of wine and resveratrol in cardiovascular disease. French paradox revisited. Exp Clin Cardiol. 2006;11(3):217-225.

21. Li HF, Chen SA, Wu SN. Evidence for the stimulatory effect of resveratrol on ca ${ }^{2+}$ actiated $\mathrm{K}^{+}$current in vascular endothelial cell. Cardiovasc Res. 2000;45(4):10351045.

22. Rauchcova H, Ledvinkova J, Kalous M, Drahota $Z$. The effect of lipid peroxidation on the activity of various membrane bound ATPases in rat liver, kidney. Int J Biochem Cell Biol. 1995;27:251-255.

23. Hazarika A, Sarkar SN. Effect of isoproturon pre-treatment on the biochemical toxicol dynamics of anilofs in male rats. Toxicology. 2001;165(2-3):8795.

24. Atef AA, Ezz MK. Evaluation of the antioxidant effects of resveratrol against hyperglycemia-induced oxidative stress in type 2 diabetic rat model. J. Appl. Sci. Res. 2012;8(3):1576-1584.

25. LV XC, Zhou HY. Resveratrol protects $\mathrm{H} 9 \mathrm{c} 2$ embryonic rat heart derived cell from oxidative stress by inducing autophagy: Role of p38 mitogen-activated protein kinase. Can J Physiol Pharmacol. 2012; 90(5):655-62.

26. Kim TM, Chung HM, Lee $\mathrm{KH}$, Lee $\mathrm{GH}$, Choi EJ, et al. The cardioprotective effects of resveratrol via anti-apoptosis in hypoxia injury of myocardial cells. Korean Circ J. 2007;37(9):408-413.

27. Younce CW, Burmeister MA. Exendin 4 attenuates high glucose-induced cardiomyocyte apoptosis via inhibition of endoplasmic reticulum stress and 
activation of SERCA 2a. Am J Physiol Cell Physiol. 2013;304(6):C508-518.

28. Zou Y, Yao A, Zhu W,Kudoh S, Hiroi Y, Shimoyama, et al. Isoproterenol activates extracellular signal- regulated protein kinase in cardiomyocytes through calcineurin. Circulation. 2001;104(1):102108.

29. Yagi K, Ohkawa $\mathrm{H}$, Ohishi $\mathrm{N}$, et al. Reaction of linoleic acid hyperoxide with thiobarbituric acid. J Lipid Res. 1979;19(8): 1053-1057.

30. Ohkawa H, Ohisi N, Yagi K. Assay for lipid peroxidation in animal tissues by thiobarbituric acid reaction. Anal Biochem. 1979;95(2):351-358.

31. Moron MS, Depierre JW, Mannervik B. Levels of glutathione, glutathionereductase and glutathione S-transferase activities in rat lung and liver. Biochim. Biophys. Acta. 1979;582(1):67-78.

32. Aziz MT, EL lbrashy IN, Mikhailidis DP, Rezq AM, Wasser MA, et al. Signaling mechanisms of a water soluble curcumin derivative in experimental type 1 diabetes with cardiomyopathy. Diabetol Metab Syndr. 2013;5(1):13.

33. Hjerten S, Pan H. Purification and characterization of two forms of a low affinity calcium ion ATPase from erythrocyte membranes. Biochimica et Biophysica Acta. 1983;728(2):281-288.

34. Jorgensen PL. Purification of $\mathrm{Na}^{+} \mathrm{K}^{+}$ ATPase: Enzyme sources. Preparative problems, and preparation from mammalian kidney. Methods Enzymol. 1988;156:29-43.

35. Ohinishi T, Suzuki T, Suzuki Y, Ozawa K. A comparative study of plasma membrane $\mathrm{Mg}^{2+}$ ATPase activities in normal. Biochim Biophys Acta. 1982;684(1):67-74.

36. Flohe L, Gunzler WA, Loschen G. In trace metal in Health \& Disease (Kharasch $\mathrm{N}$ .ed). Raven: New York; 1979.

37. Pandey KB, Rizvi SI. Resveratrol may protect plasma proteins from oxidation under conditioned of oxidative stress in vitro. J. Braz. Chem. Soc. 2010;21(5):909913.

38. Kimes BW, Brandt BL. Properties of a colonal muscle cell line from rat heart. Exp Cell Res. 1976;15;98(2):367-381.

39. Hescheler J, Meyer R, Plant S, Krautwurst D, Rosenthal W, Schultz G. Morphological, biochemical and electrophysiological characterization of a clonal cell (H9c2) line from rat heart. Circ Res. 1991;69(6):14761486.

40. Eckel J. Direct effects of glimepiride on protein expression of cardiac glucose transporters. Horm Metab Res. 1996; 28(9):508-511.

41. Gurusamy N, Lekli L, Mukherjee S, Ray D, Ahsan MK, Gherqhiceanu M, et al. Cardioprotection by resveratrol: A novel mechanism via autophagy involving the mTORC2 pathway. Cardiovasc Res. 2010; 86(1):103-112.

42. Davi G, Falco A, Patrono C. Lipid peroxidation in diabetes mellitus. Antioxid Redox Signal. 2005;7(1-2)256-268.

43. Young IS, Woodside JV. Antioxidants in health and disease. J Clin Pathol. 2001;54(3):176-186.

44. Leonard SS, Xia BH, Stinefelt B, Klandorf $\mathrm{H}$, Harris GK, et al. Resveratrol scavenges reactive oxygen species and effects radical-induced cellular response. Biochem Biophys Res Commun. 2003;309(4):10171026.

45. Melov S. Animal models of oxidative stress, aging and therapeutic antioxidant interventions. Int $\mathrm{J}$ Biochem Cell Biol. 2002;34(11):1395-1400.

46. Rizvi SI, Zaid MA. Intracellular reduced glutathione content $\mathrm{n}$ normal and type 2 diabetic erythrocytes: Effect of insulin and (-) Epicatechin. J Physiol Pharmacol. 2001;52(3):483-488.

47. Rizvi SI, Maurya. Markers of oxidative stress in erythrocytes during aging in humans. Ann N Y Acad Sci. 2007;1100: 373-382.

48. Sharmila ST, Rajdurai M. Preventive effect of Bio-AQ on cardiac markers, Lipids \& membrane bound enzymes in isoproterenol induced myocardial infarction in rats. Asian J Pharm Clin Res. 2012;5(2):107-113.

49. Vajreswari W, Narayana reddy K. Effect of dietary fats on some membrane-bound enzyme activities, membrane lipid composition and fatty acid profiles of rat heart sarcolemma. Lipids. 1992;27(5):339343.

50. Ithayarasi AP, Devi CS. Effect of alpha tocopherol on lipid peroxidation in isoproterenol induced myocardial infarction in rats. Indian J Physiol Pharmacol. 1997;41(4):369-376.

51. Finotti $P$, Palatini $P$. Reduction of erythrocyte $\left(\mathrm{Na}^{+} / \mathrm{K}^{+}\right)$ATPase activity in 
type I (insulin-dependent) diabetic subjects and its activation by homologous plasma. Diabetologia. 1986;29(9):623-628.

52. Levy J, Rempinski D, Kuo TH. Hormone specific defect in insulin regulation of
$\left(\mathrm{Ca}^{2+} / \mathrm{Mg}^{2+}\right)$ adenosine triphosphatase activity in kidney membranes from streptozotocin non-insulin dependent diabetic rats. Metabolism. 1994;43(5):604613.

(c) 2016 Uma and Sreepriya; This is an Open Access article distributed under the terms of the Creative Commons Attribution License (http://creativecommons.org/licenses/by/4.0), which permits unrestricted use, distribution, and reproduction in any medium, provided the original work is properly cited.

Peer-review history:

The peer review history for this paper can be accessed here: http://sciencedomain.org/review-history/14228 